\title{
Programa escola de pais: uma proposta de intervenção junto a pais de adolescentes institucionalizados
}

\author{
School for parents program: a proposal for intervention with parents of \\ institutionalized adolescents
}

\section{Helen Patricia Paulino Furtado* Carla Maria Lima Braga **}

\begin{abstract}
Resumo:
O artigo apresenta o Programa Escola de Pais, desenvolvido no Centro de Socioeducação Londrina II com os familiares dos adolescentes internados na instituição. Constitui-se em uma modalidade de ação construtiva e emancipatória em consonância com o objetivo da instituição, qual seja o de promover o desenvolvimento integral dos adolescentes. Proporciona apoio, escuta, orientação e aprendizado aos pais, focalizando a melhoria e o fortalecimento das relações familiares. O programa atende aos dispositivos legais estabelecidos pela Constituição Federal de 1988 e pelo Estatuto da Criança e do Adolescente, bem como aos princípios do SINASE - Sistema Nacional de Atendimento Socioeducativo, cujas diretrizes reconhecem a importância e a responsabilidade da família para o desenvolvimento infantojuvenil. As ações teóricas e práticas são fundamentadas no referencial teórico psicanalítico, sobretudo nos escritos do pediatra e psicanalista D. W. Winnicott acerca da Teoria do Amadurecimento Pessoal, a respeito da adolescência e da tendência antissocial. Este trabalho foi desenvolvido a partir de intervenção junto a famílias, e a avaliação qualitativa das reuniões foi realizada por meio da análise do discurso dos participantes, tendo sido utilizado o método interpretativo psicanalítico. A intervenção, mediante a troca de experiências em grupo, possibilitou aos pais uma reflexão sobre a responsabilidade da função parental necessária a formação do indivíduo.
\end{abstract}

Palavras-chave: Adolescentes. Família. Intervenção. Instituição. Desenvolvimento integral. Psicanálise. Socioeducação

\begin{abstract}
:
The article presents the Parents School Program, developed in Central social education-Londrina II with the families of adolescents admitted to the institution. It constitutes a form of constructive action and emancipatory in line with the main objective of the institution, which is to promote the integral development of social students. Provides support, listening, learning and
\end{abstract}

\footnotetext{
* Psicóloga pela Universidade Estadual de Londrina Especialista em Psicologia Clínica e Psicanálise pela Universidade Estadual de Londrina. Psicóloga do Centro de Socioeducação de Londrina II Coordenadora do Programa Escola de Pais do CENSE Londrina II. hellenpatfurtado@yahoo.com.br

** Psicóloga. Docente do Departamento de Psicologia e Psicanálise da Universidade Estadual de Londrina. Mestre em Educação pela Uel. Doutora em Psicologia pela PUCCamp. carlabraga@sercomtel.com.br
} 
guidance to parents, focusing on the improvement and strengthening of family relationships, aiming at their harmony. The program attends the legal requirements established by the Federal Constitution and the Statute of Children and Adolescents, and the principles of SINASE -National SocioEducational Services, the guidelines recognize the importance of family and responsibility of the family for the child-juvenille development. The. The intervention, through the exchange of experiences in groups, allowed parents to a reflection on the responsibility of the individual's training required parentaltheoretical and practical actions are based on psychoanalytical theory, especially in the writings of the pediatrician and psychoanalyst D. W. Winnicott on Theory of Aging staff, about the adolescence and antisocial tendency. This paper was developed based in the intervention among the families, and qualitative assessment of the meetings was conducted by analyzing the speech of the participants, having been used the psychoanalytic method of interpretation. The intervention, through the exchange of experiences in groups, allowed parents to a reflection on the responsibility of the individual's training required parental

Keywords: Adolescents. Family. Intervention. Institution. Integral development. Psychoanalysis. Socio-education

\section{Introdução}

O presente trabalho apresenta uma proposta de intervenção junto aos familiares de adolescente institucionalizados, decorrente de cumprimento de medida socioeducativa de internação. A proposta de tal intervenção diz respeito à necessidade de fortalecer os vínculos familiares, que no contexto atual (em função do cumprimento de internação) se apresentam extremamente fragilizados, assim como oferecer um suporte emocional e informativo para os pais poderem compreender seus filhos, de forma a contribuir consequentemente, de maneira mais adequada, na formação destes.

Dessa forma, implantou-se, no Centro de Socioeducação - CENSE - Londrina II, o Programa Escola de Pais, estabelecido pela Portaria no 10/2010 de 10 de abril de $2010^{1}$. As suas finalidades encontram-se fixadas no artigo $2^{\circ}$ da referida portaria:

I - fortalecer o vínculo entre o CENSE Londrina II e as famílias dos adolescentes internados; II - coordenar esforços de cooperação entre os pais e o CENSE Londrina II visando o melhor atendimento do adolescente e da família; III - oportunizar aos pais a aquisição e a ampliação de

\footnotetext{
1 Portaria como ato normativo interno da instituição, não requer publicação no diário oficial,
} necessariamente, porque o âmbito da normatização é interno ao CENSE e não abrange o público em geral. 
conhecimentos e valores que fortaleçam o relacionamento e o convívio familiar e comunitário; IV - favorecer aos pais a reflexão sobre ações e posturas promotoras do desenvolvimento integral dos membros da família; $\mathrm{V}$ - fornecer aos pais informações, orientações e apoio para o exercício da função social da família; VI - ampliar a comunicação entre os pais e os filhos com vista a interação mais harmoniosa e saudável; VII- Fortalecer a família para a superação de dificuldades, impasses e desafios relacionados ao retorno do adolescente ao convívio familiar e comunitário (PARANÁ, 2010)

O programa teve início a partir da solicitação do gestor do $\operatorname{CENSE}^{2}$ à época, o qual diligenciou a fim de que se implementassem as atividades necessárias ao cumprimento dos preceitos legais estabelecidos pelo Estatuto da Criança e do Adolescente (Lei 8.069/90), em seu artigo 94, incisos I, II, IV e V. A solicitação também visava promover a ação adequada do Estado, inserindo, em seu nível operacional, um trabalho contínuo e independente da transitoriedade dos governos. Da forma como instituído, o mencionado Programa configura um modo de participação da família no processo socioeducativo em complemento às demais ações planejadas pela equipe profissional do CENSE.

Do mesmo modo, a experiência nos atendimentos aos adolescentes desta instituição, assim como às suas famílias, reafirmam sobre as necessidades familiares, que estão muito além das condições socioeconômicas adversas. Há uma variedade de dificuldades no estabelecimento e na natureza dos vínculos familiares, os quais são elementos constitutivos do envolvimento desses adolescentes com a prática de atos infracionais. O cotidiano profissional demonstra que apesar da função precípua de proteção e cuidado dos filhos, muitas famílias não logram êxito em atender às suas necessidades afetivo-emocionais, de maneira a favorecer seu desenvolvimento integral. Podemos observar que os grupos familiares, além das dificuldades advindas de suas condições objetivas de vida, apresentam demanda por escuta, apoio e orientação para a superação dos conflitos referentes ao relacionamento familiar e ao cuidado com os filhos. As famílias se mostram imersas em dificuldades de toda ordem, oferecendo aos seus membros os cuidados proporcionais aos recursos materiais, emocionais e afetivos possíveis em seus contextos, nem sempre suficientes ao desenvolvimento humano. Verificamos, também, o desejo e a necessidade dos

\footnotetext{
${ }^{2} \mathrm{O}$ gestor do CENSE II à época Sr. Julio César Botelho.
} 
adolescentes de obter estabelecimento, reaproximação e/ou fortalecimento dos vínculos familiares.

A reflexão acerca de tais questões encontrara respaldo na literatura psicanalítica, principalmente na teoria do amadurecimento pessoal e da tendência antissocial descrita por D. W. Winnicott. A partir disso, houve a necessidade de se realizar um trabalho de intervenção com essas famílias, com vistas à melhoria e ao fortalecimento da qualidade das relações interpessoais, provendo auxílio ao exercício das funções parentais. Além disso, um trabalho nesses termos materializaria o reconhecimento dos teóricos e profissionais da Psicologia, bem como da diversidade de profissionais da área de atendimento infantojuvenil.

A intervenção familiar também concretizaria os dispositivos legais que regulam o atendimento ao público infantojuvenil, que, em sua essência, reconhecem a importância da família para o desenvolvimento integral de crianças e adolescentes. Tais dispositivos não apenas estimulam a convivência familiar, mas também procuram garanti-la por se tratar de direito dessa clientela específica. Assim, são estabelecidas diretrizes para que a convivência seja harmoniosa, prevendo-se a utilização de recursos e estratégias para auxiliar a família no tocante à construção de um ambiente adequado.

As ações do programa em questão, como já mencionamos, são fundamentadas no referencial teórico psicanalítico. Importante a concepção de Soifer (1982, p. 11) acerca da imprescindibilidade da família como "organismo na qual cresce, evolui, amadurece e morre o ser humano, sendo destinado essencialmente ao cuidado da vida - tanto individual como social - onde se dão e se aprendem as noções fundamentais para a consecução de tal fim".

Muitos autores psicanalíticos já nos mostravam a relevância em trabalhar com a família, mas a escolha dos pressupostos de D.W.Winnicott é com base em que tal teoria trabalha com a ideia de que todo o indivíduo humano é dotado de uma tendência inata ao amadurecimento desde que acompanhado de um ambiente facilitador. $\mathrm{O}$ autor enfatiza que as condições ambientais favorecem a constituição do indivíduo e a capacidade de se relacionar com o mundo e com os objetos externos. Sendo assim, a 
tese do autor de que um ambiente facilitador é essencial para o desenvolvimento infantojuvenil saudável ${ }^{3}$ está subjacente às ações do programa.

As famílias dos adolescentes em cumprimento de medida de internação são desfavorecidas economicamente e têm maior dificuldade para encontrar apoio às suas problemáticas relativas aos relacionamentos interpessoais. A elas são impostas preocupações extremas com questões básicas de sobrevivência, vivência em contextos de violência e desrespeito de seus direitos fundamentais. No entanto, as dificuldades de promover o desenvolvimento infantojuvenil são encontradas em famílias de todas as classes sociais, tendo em vista a presença de sintomas comuns relacionados ao alcoolismo, ao uso de drogas, à violência, à depressão e aos comportamentos antissociais em diferentes níveis socioeconômicos.

O programa do CENSE II desenvolve suas ações com o cuidado de não culpabilizar as famílias por suas dificuldades. Ao contrário, o trabalho é realizado no intuito de apoiar, auxiliar e fortalecer os grupos familiares e de instrumentalizá-los no trato das questões que os envolvem, em especial, referentes à infância e à adolescência. Acima de tudo, as atividades desenvolvidas têm por objetivo o melhor exercício das funções parentais, com vistas à melhoria das relações interpessoais, dada a necessidade premente de preparar as famílias para o retorno do adolescente ao seu convívio após o cumprimento de medida socioeducativa de internação.

Nesse sentido, o objetivo principal do trabalho é apresentar uma discussão referente à implantação do Programa Escola de Pais do CENSE II. A partir disso, reafirmar a importância de intervenções no contexto familiar dos adolescentes que cumprem medida socioeducativa de internação, com enfoque na melhoria das relações humanas. A metodologia utilizada para a elaboração deste artigo compõe-se da intervenção propriamente dita com os familiares e da avaliação de cada encontro a partir do referencial teórico adotado. As reuniões foram avaliadas por meio do método qualitativo de análise do discurso dos familiares, com uso do método

\footnotetext{
${ }^{3}$ Segundo Winnicott (2005), a realidade de dependência da criança de seu ambiente constitui-se no mais importante dos fatores de seu desenvolvimento. O autor define o ambiente facilitador como o contexto que possibilita progresso constante dos processos maturacionais da criança em conformidade com o potencial herdado. $\mathrm{O}$ ambiente é constituído por todos os membros do núcleo familiar, pelas demais pessoas que convivem com a criança e seus inter-relacionamentos, bem como por todo o ritual que envolve o cuidado infantojuvenil, considerando-se ainda condições, objetos e materiais que o envolvem.
} 
interpretativo psicanalítico. Os aspectos considerados nessa avaliação foram: a mudança no discurso dos familiares, a dinâmica interpessoal e a reflexão e/ou ressignificação de conflitos.

\section{A família}

Com vistas a apresentar a fundamentação teórica utilizada neste trabalho, expomos, a seguir, seus principais elementos. Nesta seção, comentaremos acerca da família, dos contextos das relações familiares e dos dispositivos legais relativos a esse grupo peculiar. Na próxima seção, sintetizaremos as questões relativas à adolescência. Cabe ressaltarmos a importância da Psicanálise e de seus pesquisadores como substrato científico deste artigo e das ações realizadas no CENSE II.

\section{A família e o desenvolvimento humano}

Os principais expoentes da psicanálise, Freud, Klein, Winnicott, autores consagrados como Aberastury, Knobel, Soifer, assim como os autores contemporâneos como Outeiral, Safra ou Zimerman, independentemente de sua orientação conceitual ${ }^{4}$ reconhecem a família como elemento essencial ao desenvolvimento humano. Corroborou-se, ao longo do tempo, que ela é primordial na estruturação da identidade do indivíduo adulto.

A literatura específica apresenta várias definições de família, porém devemos nos atentar às profundas modificações na configuração do grupo familiar no decorrer do processo histórico. Essas transformações têm modificado as relações intrafamiliares, repercutindo no padrão de cuidado oferecido aos membros descendentes e, por conseguinte, na formação da identidade dos adultos. Há muitos aspectos culturais e sociológicos envolvidos nesse processo de mudanças, os quais devem ser considerados, bem como novos conceitos, valores, expectativas e papéis a serem desempenhados por seus membros.

Outeiral (2003) descreve o contexto atual como formado por grupos familiares reduzidos, constituídos pelos pais e um ou dois filhos. Também são comuns as famílias

\footnotetext{
${ }^{4}$ A orientação conceitual pode inclinar-se mais para o foco pulsional ou para o foco ambiental.
} 
monoparentais (chefiadas por mulheres), e é menos frequente a função paterna. Observamos uma diversidade nas famílias reconstituídas, havendo a junção de filhos de outras uniões de cada cônjuge. Percebemos, ainda, distanciamento da família recentemente composta em relação à família de origem, havendo menor contato com relações de parentesco.

Além disso, estando ambos os pais inseridos no mercado de trabalho, o tempo dedicado ao cuidado com os filhos tornou-se menor do que se via em outras épocas. Em consequência, dilata-se a necessidade de recursos como creches, berçários e escolas infantis, que se tornam as responsáveis de fato pela maternagem das crianças. Todavia, tais serviços não estão ao alcance de toda a população que os demanda, e não raro se constituem em locais pouco adequados ao desenvolvimento infantil.

De todo modo, devemos conhecer as definições teóricas de família, como a de Pichon Rivière (1970 apud SOIFER, 1982). Para eles, respectivamente, a família se apresenta como "[...] estrutura social básica, que se configura pelo entrejogo de papéis diferenciados (pai, mãe, filho), entrejogo que constitui o modelo natural de interação em grupo" e como:

[...] um núcleo de pessoas que convivem em determinado lugar, durante um lapso de tempo mais ou menos longo e que se acham unidas (ou não) por laços consanguíneos. Este núcleo por seu turno se acha relacionado com a sociedade, que the impõe uma cultura e ideologia particulares, bem como recebe dele influências específicas (RIVIÈRE apud SOIFER, 1982, p. 22).

Zimerman (1999) acrescenta que a família é um campo dinâmico no qual agem tanto os fatores conscientes quanto os inconscientes. De acordo com o autor, esses fatores:

[...] circulam em todos os níveis por meio de uma rede de necessidades, desejos, demandas, relações objetais, ansiedades, mecanismos defensivos, mal entendidos da comunicação, segredos ocultos ou compartilhados, afetos contraditórios, entre outros [...]. Há também, toda uma transmissão de valores e de significações, identificações, ambições e expectativas de uma geração a outra (ZIMERMAM, 1999, p. 104).

Reconhecendo a família como ambiente essencial para o desenvolvimento do indivíduo, desde o início até o final de sua formação, Soifer (1982, p. 23) especifica as funções que o grupo familiar precisa desempenhar para haver esse desenvolvimento: 
"o ensinamento do cuidado físico, da capacidade de relacionamento familiar e social, a aptidão para a atividade produtiva e para a inserção profissional, e a transmissão de normas culturais para a convivência em geral".

Os pressupostos teóricos de D. W. Winnicott contribuem para melhor compreender a família, especialmente sua teoria acerca do amadurecimento pessoal. ${ }^{5}$ Este autor, além de seus trabalhos em consultório, contribuía com palestras divulgadas em rádio, de modo a qualificar os diversos ambientes onde estariam as crianças, a mãe, a família e a escola. Winnicott, pediatra e psicanalista, com vasta experiência no atendimento de bebês, crianças, adolescentes e suas famílias, desenvolveu sua teoria com base na qualidade ambiental, principalmente no que se refere à qualidade da relação dos membros do grupo familiar inicialmente com o bebê e, posteriormente, com a criança e o adolescente.

A teoria winnicottiana fundamenta-se no princípio de que existe, em todo ser humano, uma tendência inata ao amadurecimento emocional. Entretanto, para o indivíduo atingi-lo, são necessárias condições ambientais favoráveis. Segundo o autor, o longo caminho a percorrer nesse processo é viável mediante a existência de um ambiente facilitador. $\mathrm{O}$ ambiente mostra-se agente passivo das influências de outrem, mas, reciprocamente, influencia o padrão de conduta de cada membro familiar e a família em sua totalidade. Sendo assim, o indivíduo cresce e se desenvolve num ambiente que facilita ou traumatiza nesse processo.

Quanto ao estágio inicial de desenvolvimento, o autor valoriza a função materna, pois, para ele, a mãe é o primeiro ambiente da criança, sendo o principal fator estruturante do psiquismo desta. As falhas na função materna prejudicam o processo maturacional da criança. Como resultado, podem ocorrer distorções na personalidade do indivíduo, a exemplo da psicose.

Apesar de utilizar-se do termo mãe, Winnicott (2000), explica não se tratar especificamente da mãe biológica, mas da função materna, a qual pode ser exercida por qualquer pessoa, de qualquer sexo. Desse modo, os laços afetivos se formam a partir de elementos que transcendem a questão de parentesco. Tais laços dependem

\footnotetext{
${ }^{5}$ A palavra pessoal indica o respeito que o autor tinha com a singularidade e a individualidade de cada criança em seu desenvolvimento.
} 
essencialmente do comportamento do adulto na interação com a criança. As características do adulto, mesmo sutis, são as mais relevantes para estabelecer vínculos com a criança, como a capacidade de envolvimento emocional com ela, a sensibilidade no trato, a resposta às suas demandas e o acolhimento.

A teoria winnicottiana indica a necessidade de haver uma "mãe suficientemente boa" nos estágios iniciais e também nos outros estágios do processo evolutivo do indivíduo. ${ }^{6}$ Tem-se, em vista, o desenvolvimento humano em conformidade com o potencial herdado, sem distorções demasiadas na personalidade da criança. Winnicott define essa "mãe suficientemente boa" como a que apresenta alto nível de identificação com o seu bebê. O processo de identificação é natural e acontece com as mães que não apresentam demasiados problemas emocionais. Estes, se intensos, prejudicam a interação mãe-filho, em virtude de sua menor disponibilidade de atendimento às demandas de atenção e de cuidado da criança.

Consoante Winnicott (2000), o estado de preocupação materna primária ${ }^{7}$ capacita a mãe para oferecer ao bebê exatamente o cuidado de que ele necessita em termos físicos e emocionais, a fim de criar uma zona de ilusão na qual se estabeleça um estado fusional entre ambos. No entanto, esse estado é temporário, e a mãe tende a retornar à sua condição original, gradativamente diminuindo o seu nível de adaptação às necessidades da criança. Isso possibilita o seu desenvolvimento, a partir do princípio de realidade que resulta em diminuição do seu sentimento de onipotência.

Winnicott (1983) descreve o processo de amadurecimento humano em três estágios principais, os quais se sucedem a partir da relação da mãe com o seu bebê: dependência absoluta, dependência relativa e rumo à independência. O primeiro estágio, de dependência absoluta, caracteriza-se pela total dependência do bebê em relação à função materna. Para não ocorrerem distorções no desenvolvimento

\footnotetext{
${ }^{6}$ É de suma importância esclarecer que o termo "mãe suficientemente boa" traduz uma relação de normalidade que contempla os estados de humor, de cansaço, de desespero e de falhas, inclusive. Sendo assim, não se refere a um estado de perfeição mecânica, mesmo porque isso não existe entre a espécie humana.

7 Trata-se de uma condição psicológica especial da mãe nas semanas anteriores e posteriores ao nascimento de seu filho, favorecida pelo seu envolvimento corporal e também de sua elaboração imaginativa, denominada "preocupação materna primária" (DAVIS; WALLBRIDGE, 1982, p. 108).
} 
infantil, a função materna deve ser desempenhada por um adulto o qual se apresente como "mãe suficientemente boa".

Isso é possível se houver o estado de "preocupação materna primária", o adulto deve identificar-se em alto nível com o seu filho, provendo-lhe exatamente aquilo de que ele necessita em cada momento específico. Nessa fase, a criança não apresenta condições de reconhecer a necessidade desse cuidado, apenas tira proveito ou sofre os efeitos negativos dessa maternagem, a qual é adequada ou inadequada às suas necessidades.

O proveito significa a continuidade do seu processo maturacional de acordo com o potencial herdado, incluindo o senso de ser amado e de segurança. Em contrapartida, os efeitos negativos se referem à interrupção desse processo. Pode haver instalação de defesas e até desenvolvimento de quadros clínicos letais ou que conduzam à psicose. O bebê encontra-se em condição fusional com sua mãe, já que a maternagem "suficientemente boa" estabelece a zona de ilusão necessária para o bebê sentir que todo seu ambiente, o qual inclui sua mãe, trata-se de si mesmo.

O segundo estágio, a dependência relativa, caracteriza-se pela adaptação do bebê à desadaptação gradual da mãe em relação ao provimento de suas necessidades. Tal processo é natural e possibilita o desenvolvimento da criança, pois oferece condições para seu afastamento progressivo da figura materna, seguindo rumo à independência. A mãe, depois o pai, e ainda mais tarde a família proveem os cuidados relativos às necessidades da criança.

O terceiro estágio, rumo em direção à independência, alude à criança da fase pré-escolar e púbere. Nessa etapa, se os processos dos ciclos anteriores foram normais, saudáveis, ela apresenta maior condição de prescindir dos cuidados maternos. Podemos asseverar, logo, que o desenvolvimento intelectual e a internalização dos cuidados maternos permitem o desenvolvimento da confiança no ambiente e a ampliação da vida social. Em consequência, o indivíduo apresenta maior capacidade de lidar com o mundo em sua complexidade.

Devemos salientar que nunca se atinge o estado de independência absoluta, o indivíduo saudável não se torna isolado, mas estabelece uma relação de interdependência com o ambiente ao longo de sua vida. No tocante a isso, Winnicott 
considera como parâmetros para o início da vida adulta a inserção social por meio do trabalho, talvez o estabelecimento de união afetiva ou uma conciliação entre a identificação materna e a construção de sua própria identidade.

Apesar da ênfase na função materna nos estágios iniciais do desenvolvimento humano, Winnicott (1983) explica que o pai toma parte do processo, todavia sua função mais importante (no estágio inicial do desenvolvimento do bebê) é a de suporte à mãe na sua relação e cuidados com o bebê. Idealmente, o indivíduo "pai" deve encarregar-se de proteger a mãe de problemas externos, tendo em vista o estado de "preocupação primária" no qual ela se encontra, nesse contexto, apenas interessa à mãe o seu bebê. Quando não há um pai, é fundamental que alguém exerça a função paterna, a fim de proporcionar a referida proteção à mãe.

Acrescenta Winnicott (apud DAVIS; WALLBRIDGE, 1982) que o pai, por suas características diferentes da mãe, minora as obrigações dela no exercício de suas funções, porque ela não precisará ter em si, simultaneamente, características opostas, conflitantes e/ou contraditórias. Além disso, a partir de sua autoridade, o pai representa, para a criança, o ambiente indestrutível. Este é imprescindível à constituição e controle da agressividade da criança, visto que ela sentirá segurança de que o ambiente não sucumbirá ao seu destrutivismo.

Zimerman (1999), por sua vez, sustenta que a presença física e afetiva do pai contribui para o processo de separação-individuação da díade mãe-filho. Apresentando-se como terceiro elemento, transforma a relação diádica, mãe-bebê, em uma relação triangular, mãe-pai-bebê, promovendo, assim, o desenvolvimento efetivo da criança. O autor argumenta que a função paterna inflige adequadas frustrações à criança, por meio da colocação e do reconhecimento de limitações, bem como da aceitação das diferenças. Tais situações impulsionam, necessária e dolorosamente, a transição do princípio do "prazer-desprazer" vivido inicialmente pela criança para o princípio da realidade. As frustrações também estimulam as funções do ego infantil, em especial a formação da capacidade para pensar.

Zimerman (1999) afirma ainda que, além dos aspectos envolvendo a figura paterna individualmente, a vinculação entre os progenitores é elemento importante da família, e se apresenta essencial o significado da criança para os pais em suas 
fantasias conscientes e/ou inconscientes desde o momento em que ela foi concebida. Tais elementos são relevantes quanto à possibilidade de se preocupar e de cuidar de cada criança durante todo o seu desenvolvimento.

A transgeracionalidade, segundo explana Zimerman (1999), mostra-se outro componente básico da relação de pais e filhos. Trata-se da internalização, em cada um dos progenitores, dos valores, estereótipos e conflitos de suas famílias originais. Por conta da internalização, há forte tendência de que sejam repassados aos filhos. Dessa forma, não há apenas uma reedição, nos próprios pais, dos conflitos internalizados de sua família de origem, mas também a transmissão desses conflitos para os seus descendentes. O ciclo de transmissão, de internalização e de retransmissão envolve, ao menos, três gerações influenciando a constituição psíquica e a identidade dos filhos.

A influência abrange, por outro lado, as características individuais em geral dos pais e a relação estabelecida entre eles. A imagem e o valor de um em relação ao outro constituirão, em grande parte, as representações internas que o indivíduo tem de cada um dos pais e, por conseguinte, de si mesmo. Este fenômeno se refere às identificações do indivíduo que estão relacionadas à formação de sua própria identidade e sentimento de autoestima. O fenômeno relaciona-se, simultaneamente, com a designação e com a definição de papéis a serem cumpridos dentro da família e nos demais contextos.

Diante do exposto, verificamos ser elementar para o desenvolvimento infantojuvenil saudável uma família com a mínima estruturação em termos de hierarquia no ordenamento de papéis e atribuições de seus membros. Nessa perspectiva, o Programa Escola de Pais, do CENSE II, intenta, por meio de suas ações, oferecer apoio e orientação para o melhor exercício das funções parentais, buscando a harmonia das relações familiares, de modo a repercutir positivamente no padrão de cuidados oferecidos aos filhos.

\section{A família e os dispositivos legais}

A Constituição Federal reconhece e protege a entidade familiar nos termos do artigo 226: “A família, base da sociedade, tem especial proteção do Estado. [...] § 4은 
Entende-se, também, como entidade familiar a comunidade formada por qualquer dos pais e seus descendentes" (BRASIL, 2010a, p. 44). Ademais, o parágrafo 5o do artigo 226 estabelece a base do poder familiar, sendo que os "[...] direitos e deveres referentes à sociedade conjugal serão exercidos igualmente pelo homem e pela mulher." (BRASIL, 2010a, p. 44). Nos artigos 227, 229 e 230 da Carta, encontram-se ainda os deveres atribuídos aos membros da entidade familiar. Esses comandos constitucionais deram origem a diversas leis sociais, como o Estatuto da Criança e do Adolescente e o Estatuto do Idoso, por exemplo. Já no contexto internacional, tratados e convenções expressam o esforço das nações para definir direitos, garantias e proteção à entidade familiar e aos seus membros.

Os documentos legais estabelecem, em essência, que crianças e adolescentes não podem ser concebidos de forma dissociada de sua família e de seu contexto sociocultural. O reconhecimento dos deveres familiares com seus membros e da importância desse instituto para o desenvolvimento integral infantojuvenil visa garantir não apenas a convivência familiar, mas também a fixar diretrizes para essa convivência, impondo aos pais direitos e obrigações de cuidados adequados com os filhos.

Assim, a Constituição Federal, em seu art. 229, prescreve que os pais "[...] têm o dever de assistir, criar e educar os filhos menores, e os filhos maiores têm o dever de ajudar e amparar os pais na velhice, carência ou enfermidade" (BRASIL, 2010a, p. 44). O Estatuto da Criança e do Adolescente determina, no artigo 22, que aos pais "incube o dever de sustento, guarda e educação dos filhos menores, cabendo-Ihes ainda, no interesse destes, a obrigação de cumprir e fazer cumprir as determinações judiciais" (BRASIL, 2010b, p. 4). Nessa mesma perspectiva, a Convenção dos Direitos da Criança, em seu art. 18, preceitua que os "Estados-partes envidarão os maiores esforços para assegurar o reconhecimento do princípio de que ambos os pais têm responsabilidades comuns na educação e desenvolvimento da criança" (BRASIL, 1990, p. 7).

Além desses deveres individuais, há o dever, em corresponsabilidade com a sociedade e com o Estado, de atender ao art. 5o do Estatuto da Criança e do Adolescente: "nenhuma criança ou adolescente será objeto de qualquer forma de negligência, discriminação, exploração, crueldade e opressão [...]" (BRASIL, 2010b, p. 
1), sendo dever de todos colocarem as crianças e adolescentes a salvo de qualquer condição dessa natureza. No seu artigo 18, o mesmo Estatuto estabelece ainda que é "[...] dever de todos velar pela dignidade da criança e do adolescente pondo-os a salvo de qualquer tratamento desumano, violento, aterrorizante, vexatório ou constrangedor" (BRASIL, 2010b p. 3).

A legislação também estabelece direitos da família, como o § 8 do art. 226 da Constituição Federal: “O Estado assegurará a assistência à família na pessoa de cada um dos que a integram, criando mecanismos para coibir a violência no âmbito de suas relações" (BRASIL, 2010a, p. 44). Na mesma lógica, a Convenção dos Direitos da Criança fixa o direito da família de que "os Estados-partes prestarão assistência apropriada aos pais e aos representantes legais no exercício das suas funções de educar a criança e assegurarão o desenvolvimento de instituições e serviços para o cuidado das crianças", conforme Art. 18- 2 (BRASIL, 1990, p. 7)

Em se tratando especificamente de adolescentes, os quais cumprem medida socioeducativa, o Sistema Nacional de Atendimento Socioeducativo - SINASE ${ }^{8}$ firmou a seguinte diretriz pedagógica relacionada à família:

[...] a participação ativa da família e da comunidade em seus processos socioeducativos. Define que as práticas sociais devem oferecer condições reais, por meio de ações e atividades programáticas à participação ativa e qualitativa da família no processo socioeducativo, possibilitando o fortalecimento dos vínculos e a inclusão dos adolescentes no ambiente familiar e comunitário. As ações e atividades devem ser programadas a partir da realidade familiar e comunitária dos adolescentes para que em conjunto-programa de atendimento, adolescentes e familiares - possam encontrar respostas e soluções mais aproximadas de suas reais necessidades [...] (BRASIL, 2006, p. 49).

Observando as normas das legislações citadas, podemos afirmar que o CENSE Londrina II, por meio do Programa Escola de Pais atende principalmente ao dever constitucional de auxiliar os pais ou seus representantes legais quanto ao exercício de suas funções. O programa também efetiva os dispositivos legais específicos que consideram a importância da família para o desenvolvimento integral de crianças e

\footnotetext{
8 Trata-se de um conjunto ordenado de princípios, regras e critérios, de caráter jurídico, político, pedagógico, financeiro e administrativo, que envolve desde o processo de apuração de ato infracional até a execução de medida socioeducativa. Esse sistema nacional inclui os sistemas estaduais, distrital e municipal, bem como todas as políticas, planos, e programas específicos de atenção a esse público.
} 
adolescentes, e que estes não podem ser concebidos fora de seu contexto familiar e comunitário. Ademais, dedica-se, também, aos princípios do SINASE de envolver os responsáveis no processo socioeducativo dos filhos.

\section{A adolescência}

A Organização Mundial da Saúde (OMS) considera a adolescência como a etapa entre os 10 e 20 anos de idade. Já o Estatuto da Criança e do Adolescente (ECA) a situa entre os 12 e 18 anos de idade. Vale lembrarmos que, segundo Outeiral (2003), existem diferenças entre puberdade e adolescência. O primeiro termo refere-se ao processo biológico caracterizado pelo surgimento da atividade hormonal desencadeadora dos chamados "caracteres sexuais secundários". O termo adolescência, de outro modo, faz referência ao fenômeno psicológico e social e, sendo assim, resulta em diferentes peculiaridades de acordo com o contexto social, econômico e cultural onde o adolescente encontra-se inserido.

Outeiral (2003) explica que a palavra "adolescência" tem dupla origem etimológica, raízes as quais representam adequadamente as singularidades desse período da vida humana. Resgatando as origens etimológicas do termo, o autor informa serem do latim ad (a, para) e olescer (crescer), expressando uma condição ou um processo de crescimento, isto é, o indivíduo apto a crescer. Adolescência também deriva de adolescer, origem da palavra adoecer. Em síntese, adolescência expressa uma aptidão do indivíduo para o crescimento físico e psicológico e, também, o adoecimento em termos de sofrimento emocional em virtude das transformações físicas e mentais características desse período.

Aberastury e Knobel (1981) caracterizam a adolescência como uma fase de transição entre a puberdade e o estado adulto, considerando que o indivíduo vivencia uma crise normativa em consequência da tarefa psíquica do estabelecimento da identidade adulta. Os autores acrescentam que, nesse processo, o adolescente precisa elaborar três lutos fundamentais, cujo resultado é uma comoção, considerada normal, denominada de Síndrome da Adolescência Normal. Esses lutos se referem a: 


\begin{abstract}
A) ao luto pelo corpo infantil perdido, base biológica da adolescência, que se impõe ao indivíduo que não poucas vezes tem que sentir suas mudanças como algo externo, frente ao qual se torna espectador impotente do que ocorre no seu próprio organismo. B) ao luto pelo papel e identidade infantis, que o obriga a uma renúncia da dependência e a uma aceitação de responsabilidades que muitas vezes desconhece, C) Os lutos pelos pais da infância, os quais persistentemente tenta reter na sua personalidade, procurando o refúgio e proteção que eles significam (ABERASTURY; KNOBEL, 1981, p. 10).
\end{abstract}

Knobel (1999, p. 29) descreve uma série de manifestações de conduta as quais constituem a síndrome:

1) Busca de si mesmo, 2) Tendência grupal, 3) Necessidade de intelectualizar e fantasiar; 4) Crises religiosas, 5) Deslocalização temporal, onde o pensamento adquire as características de pensamento primário, 6) Evolução sexual manifesta, 7) Atitude social reinvindicatória com tendências anti ou associais de diversas intensidades; 8) Contradições sucessivas em todas as manifestações de conduta, dominada pela ação, que constitui a forma de expressão conceitual mais típica deste período da vida; 9) Uma separação progressiva dos pais; 10) Constantes flutuações do humor e estado de ânimo.

Winnicott também entende a adolescência como uma fase do amadurecimento humano, considerando-a uma adaptação do indivíduo a uma nova realidade. Durante o ajuste, o adolescente aprende a lidar com a potência recém-adquirida, num processo de estabelecimento de uma identidade pessoal - trata-se da descoberta de si próprio e do estabelecimento do "eu sou". Apesar de o jovem chegar a essa fase evolutiva com padrões predeterminados pelas experiências de sua infância, há ainda muitas outras que não foram vivenciadas.

Segundo Winnicott (1975), na adolescência, os êxitos e os fracassos se revelam e se manifestam os mesmos problemas apresentados nos primeiros estágios de desenvolvimento. A imaturidade dessa fase traz conflitos à tona, mas também possibilita a manifestação da criatividade, de novas aspirações, de sentimentos e de ideias que impulsionam transformações não apenas individuais, mas também sociais. Nesse sentido, a teoria winnicottiana valoriza a imaturidade do adolescente, considerando-a essencial à evolução saudável do indivíduo, e também até benéfica para a sociedade à medida que pode impulsioná-la para um novo modo de vida. 
A adolescência implica crescimento, não apenas físico, e isso demanda tempo para ocorrer, não sendo possível nem acelerar, nem retardar o processo. No decurso desse período, os pais devem assumir a responsabilidade pela saúde física e psíquica de seus filhos. Se isso não ocorre, os jovens passarão por uma falsa maturidade, perdendo a maior vantagem da fase, a de ter liberdade de pensar e agir segundo o impulso. É característica da adolescência, a rápida alternância entre independência rebelde e dependência regressiva, ou mesmo a coexistência dos dois estados (WINNICOTT, 2005, p. 117). Tais estados configuram a busca pelo mundo adulto, causando sofrimento ao indivíduo, o que é sinal de saúde.

Para Winnicott $(2005$, p. 7), o adolescente não deve ser curado como se fosse um doente, o suporte de um ambiente facilitador deve lhe ser oferecido a fim de facilitar as várias tendências individuais e suas idas e vindas. O autor enfatiza: ninguém pode dizer que a palavra "saúde" é sinônima da palavra "fácil". Isso é especialmente verdadeiro na área de conflito entre a sociedade e seu contingente adolescente (WINNICOTT, 2005, p. 8). Gradualmente, a identidade pessoal e uma nova fase se estabelecem, Winnicott (2005) aponta como indicativos do início da fase adulta a inserção social por meio do trabalho, a possibilidade de estabelecimento de união afetiva e o estabelecimento de uma identidade pessoal conciliatório com o modelo das figuras parentais.

O processo descrito é lento e gera muitas dúvidas e confusões para o adolescente, para a família e para a sociedade. Tendo em vista tais situações, o Programa Escola de Pais, do CENSE Londrina II, atua no sentido de apoiar e de orientar os pais acerca dessa fase evolutiva. Busca-se habilitá-los a dar suporte no processo natural, todavia doloroso, em que se alternam dependência e independência até o estabelecimento da identidade adulta.

Uma abordagem diferenciada foi proposta por Winnicott para o entendimento de comportamentos antissociais de crianças e adolescentes. Consoante o autor, a privação sofrida pelo indivíduo em um período específico do desenvolvimento, manifesta-se posteriormente por meio do que se conhece por tendência antissocial. Observa-se grande abrangência em termos de etiologia e de modos de conduta: 
enurese, mentiras, agressividade, destrutividade, crueldade compulsiva, roubos e furtos, perversões, entre outros.

Winnicott (2000) explica que o desenvolvimento da tendência antissocial ocorre a partir do fracasso ambiental na etapa de desenvolvimento denominada dependência relativa o qual envolve o conceito de deprivação. ${ }^{9}$ Entende-se que a tese do autor é de que há uma tendência antissocial em crianças que tiveram em seus anos primitivos uma privação significativa do ambiente.

Quando essas perdas ocorrem, a criança interrompe seu processo maturacional para ocupar-se delas, reorganizando-se emocionalmente a partir do estabelecimento de defesas contra um ambiente sentido como agressor ou não acolhedor ou confiável. Nesse sentido, a criança passa a reagir ao ambiente que falhou ao invés de continuar crescendo e se desenvolvendo conforme o seu potencial herdado. Todavia, quando há melhora nas condições ambientais, a criança organiza ações antissociais, que constituem sua esperança de conseguir o restabelecimento do ambiente suficientemente bom, o qual ela conhece e sabe que lhe foi suprimido.

A deprivação pode se manifestar principalmente em dois tipos de condutas: reinvindicação de tempo, de dinheiro e de preocupação das pessoas e expectativa de restabelecimento de um ambiente estruturado o qual permita à criança sentir-se segura para explorar a destrutividade de sua vida instintiva. Com base nessa discussão, Braga (2009) apresenta, fundamentando-se na teoria winnicottiana, o elemento de privação em diferentes adolescentes:

[...] na raiz da tendência antissocial, há sempre uma privação ou carência. Esse elemento de privação ou carência aparece, na adolescência normal, de forma mais branda e difusa, não exigindo, portanto, as defesas em demasia. É um caso diferente do adolescente com uma privação maior, que busca obrigar o mundo a reconhecer a dívida que tem com ele. Essa cobrança pode vir acompanhada com muita violência. Os conceitos de privação e deprivação colocados por Winnicott em seus trabalhos deram originalidade à sua obra, assim como a formulação de que, quando a criança ou adolescente começam a manifestar tendências antissociais, temos um sinal de saúde, de pedido de ajuda, porque ainda resta esperança de vida (BRAGA, 2009, p. 46).

\footnotetext{
${ }^{9}$ Deprivação é o termo utilizado pelo autor para designar a perda de uma experiência boa e positiva para a criança no período de dependência relativa, por período superior àquele que ela consegue manter viva essa experiência em sua memória. Diferentemente do termo privação, que designa a inexistência dessas experiências para a criança (WINNICOTT apud ABRAHAM, 2000).
} 
Winnicott (2002, p. 135) alerta que os atos antissociais podem ser considerados como um "pedido de ajuda", já que, se atendidos, podem aplacar a angústia sentida pelo indivíduo, mas isso somente em seus estágios iniciais. Se os atos antissociais perduram até o início da adolescência, proporcionam ganhos secundários, e um furto, por exemplo, passa a ter o valor do objeto real. Dessa forma, deixam de expressar simbolicamente um pedido de ajuda, de reparação, e passam a ser mantidos a partir de outras vantagens que trazem ao indivíduo. Nesse estágio, o indivíduo tende a não sentir culpa e pode reincidir nos atos, ou, de forma mais grave, desenvolver a psicopatia, considerada por Winnicott a delinquência não curada.

O diagnóstico, nessa fase de desenvolvimento, configura-se difícil tarefa, em razão dos muitos conflitos e das alternâncias de humor e de comportamentos. Dúvidas, confusões e alterações rápidas que envolvem o quadro sintomatológico confundem-se com as atitudes desajeitadas e confusas, comuns e esperadas dos jovens nessa etapa evolutiva. O Programa Escola de Pais procura lidar com essas questões, favorecendo o (re)estabelecimento de um ambiente facilitador ao desenvolvimento do adolescente. O trabalho intenciona atenuar os conflitos interpessoais a fim de minimizar problemas no retorno do adolescente ao convívio da família, após o cumprimento da medida socioeducativa.

\section{A Instituição e sua Proposta Político-Pedagógica}

O Centro de Socioeducação Londrina II - CENSE II é uma unidade de privação de liberdade para adolescentes do sexo masculino, autores de atos infracionais, prevista no art. 123 do Estatuto da Criança e do Adolescente (ECA). Nesse local, os adolescentes cumprem a medida socioeducativa de internação. Tal medida encontrase prevista no Art. 121 do ECA e é aplicada nos casos em que os atos infracionais praticados ocorrerem mediante grave ameaça ou violência a pessoa, por reiteração no cometimento de outras faltas graves ou por descumprimento reiterado e injustificável da medida anteriormente imposta. Além disso, está sujeita aos princípios de brevidade, excepcionalidade e respeito à condição peculiar de pessoa em desenvolvimento. 
A medida de internação pode ser aplicada a adolescentes com idade entre $12 \mathrm{e}$ 18 anos incompletos, e o período de internação pode variar de 6 meses a 3 anos, com avaliação periódica a cada 6 meses no máximo, realizada por equipe técnica multidisciplinar, conforme estabelece o art. 121 do ECA. Nesses termos, o CENSE Londrina II pode atender jovens de até 21 anos incompletos e suas ações devem ser fundamentadas nos princípios da socioeducação, conforme exposto nos cadernos do Instituto de Ação Social do Paraná - IASP.

\begin{abstract}
Antônio Carlos Gomes da Costa nos propõe uma abordagem interdimensional, que envolve o adolescente em sua plenitude, suplantando a abordagem disciplinar ou interdisciplinar. [...] A educação interdimensional no trabalho com os adolescentes em conflito com a lei proposta pelo autor Antônio Carlos Gomes da Costa parte do pressuposto de que a educação é a comunicação intergeracional do humano, envolvendo conhecimentos, sentimentos, crenças, valores, atitudes e habilidades na constante troca entre educador e educando. [...] É neste sentido que a educação interdimensional é um esforço de superação da tradição da educação logocêntrica - centrada na razão (logos) - , atuando em favor de uma visão do educando em sua inteireza e complexidade. Assim, de acordo com este autor, em vez de ter como base as disciplinas do logos, a educação interdimensional trabalha o educando, levando em conta seus sentimentos (Pathos), sua corporeidade (Eros), sua espiritualidade (Mythus) e sua razão (Logos) (INSTITUTO DE AÇÃO SOCIAL DO PARANÁ, 2007, p. 20-21)
\end{abstract}

Como definido nesses documentos, o principal objetivo da socioeducação é o desenvolvimento integral dos adolescentes, preparando-os para o convívio social e para o exercício da cidadania. Para atingir esses objetivos, as ações socioeducativas são dirigidas no sentido de auxiliar o adolescente quanto ao desenvolvimento de quatro tipos de aprendizagens principais, aprender a ser, aprender a conviver, aprender a fazer e aprender a aprender. ${ }^{10}$

A visão de mundo e de sujeito que fundamenta as práticas socioeducativas, em conformidade com os documentos mencionados, é dialética e interacionista, porque contempla a dinâmica das instituições família, escola, trabalho, comunidade local, rede de serviços de atendimento, entre outras. Nessa perspectiva, todas as ações dirigidas aos adolescentes para a orientação para valores e mudanças de comportamentos que visam à reinserção social não podem estar dissociadas de seu

\footnotetext{
${ }^{10}$ Esses quatro tipos de aprendizagens estão descritos também no Relatório Jacques Delors da UNESCO Educação, um Tesouro a Descobrir (1996).
} 
contexto familiar, comunitário e social em nível macro (INSTITUTO DE AÇÃO SOCIAL DO PARANÁ, 2007). Dessa forma, a efetivação da proposta socioeducativa nos Centros de Socioeducação exige o envolvimento dos vários setores em suas diferentes abordagens e especificidades, de outras instituições governamentais e não governamentais, bem como de vários atores sociais.

Em virtude desse contexto, a tarefa primordial dos centros de socioeducação é efetivar a proposta socioeducativa, não apenas para o atendimento dos dispositivos legais encontrados no ECA, como também para atender as demandas sociais da contemporaneidade. Nessa tarefa, as unidades socioeducativas promovem ações, acontecimentos e experiências de caráter pedagógico, objetivando influenciar positivamente a vida dos adolescentes durante a permanência deles na unidade e também depois do retorno à família.

Para isso, a rotina da unidade visa ao desenvolvimento integral dos jovens, sendo composta por atividades culturais, esportivas, religiosas, artísticas, recreativas e laborais, por atendimentos psicológicos e sociais e por assistência médica e odontológica. Dentre tais ações, o Programa Escola de Pais apresenta-se como uma das modalidades de intervenção utilizadas pelo CENSE Londrina II a fim de promover o desenvolvimento integral dos adolescentes. Direciona-se aos seus familiares, contribuindo para o estabelecimento de uma rede social protetora mais favorável ao seu retorno ao convívio familiar após sua desinternação.

\section{O programa escola de pais como uma possibilidade de intervenção}

O Programa Escola de Pais foi estruturado para atender aos preceitos legais estabelecidos pelo Estatuto da Criança e do Adolescente (ECA) em seu artigo 94, incisos I, II, IV e V, bem como para responder à necessidade premente de aproximar e envolver os familiares no processo socioeducativo dos adolescentes. Nosso propósito é promover o fortalecimento e a harmonia das relações familiares, tendo em vista o retorno desses adolescentes ao convívio familiar após o cumprimento da medida de internação.

Nesse processo, consideramos o caráter de brevidade da medida socioeducativa e a concepção do adolescente como ser em desenvolvimento, cuja compreensão não 
pode ocorrer de forma dissociada de seu contexto familiar e social, em conformidade com os dispositivos legais.

Todavia, as reflexões acerca da estruturação e natureza dos vínculos familiares como elementos constitutivos do desenvolvimento da conduta antissocial, decorrentes da experiência de atendimento e acompanhamento dos adolescentes e de suas famílias, respaldados pela literatura psicanalítica, foram essenciais para a estruturação deste trabalho.

O Programa é operacionalizado por meio de encontros periódicos bimestrais, palestras e/ou oficinas, com duração de até duas horas, durante as quais há espaço para a reflexão e a partilha de temas pré-programados pela coordenação do programa em conjunto com a Direção do Centro de Socioeducação. Os temas abordados fornecem informações, orientações e apoio para o exercício da função social da família, propiciam aos pais a reflexão sobre ações e posturas promotoras do desenvolvimento integral de seus membros. Os encontros também ampliam a comunicação entre os pais e os filhos, visando a interação mais harmoniosa e saudável, e fortalecendo a família para a superação de dificuldades, impasses e desafios relacionados ao retorno do adolescente ao convívio familiar e comunitário.

As oficinas abordam temas como a função social da família, a violência doméstica e o desenvolvimento infantojuvenil, as fases de desenvolvimento psicoemocional infantojuvenil, características e cuidados específicos e a adolescência, em suas interfaces com a família e a sociedade na contemporaneidade. Nosso trabalho, durante as oficinas, abarca os objetivos de:

a) discutir a função social da família, tendo em vista o melhor exercício da função parental;

b) discutir as dificuldades, limitações, impasses e desafios encontrados pela família em relação a sua configuração, a sua dinâmica e às funções parentais, a partir da realidade da família, com vistas a superá-los;

c) discutir os efeitos da violência doméstica para o desenvolvimento infantojuvenil de forma a instrumentalizar os pais para utilizarem métodos não violentos para a resolução de conflitos; 
d) caracterizar as fases de desenvolvimento psicoemocional infantojuvenil, instrumentalizando os pais para lidar de forma mais adequada com as características e especificidades de cada etapa evolutiva;

e) caracterizar a adolescência, discutindo com os pais as características e as especificidades dessa fase de desenvolvimento e suas interfaces com a família, sociedade e contemporaneidade, com vistas à instrumentalização dos pais e minimização de conflitos.

Até o momento, em termos de avaliação do Programa, temos expressiva participação dos familiares às reuniões, fator que indica o atendimento às expectativas dos pais. Os encontros vêm se consolidando como importante espaço de expressão, apoio e orientação adequados às demandas de escuta e cuidado. A adesão dos familiares decorre também da experiência dos profissionais que realizam as intervenções, os quais primam fundamentalmente pelo estabelecimento de um ambiente acolhedor e continente das angústias das famílias. Assim, a intervenção preza primeiramente por oferecer cuidado aos cuidadores, sem acusar ou culpar a família por suas dificuldades.

A possibilidade de troca de experiências entre os familiares é outro ponto importante deste trabalho, visto que, a partir da percepção de dificuldades comuns, mesmo em contextos diferentes em termos estruturais e socioeconômicos, os participantes sentem-se menos isolados ao lidar com seus conflitos. Além disso, as contribuições de cada participante ampliam o ângulo de análise da questão em pauta, auxiliando o seu processo de compreensão, facilitando a ressignificação das experiências vividas.

Observamos que, apesar da sensibilização no que se refere à privação de liberdade dos filhos, é esta a questão que os coloca identificados, ou melhor dizendo, os pais ou familiares que se encontram ali reunidos apresentam a mesma problemática, a saber, os filhos privados de sua liberdade. Em decorrência desta identificação, os pais encontram um lugar de escuta dos iguais e não só dos profissionais envolvidos. Esta prática permitiu uma troca de experiências reais, e assim aproveitarem o momento para falar sobre sua vida permeada pela vivência de abandono, da negligência e da violência, os quais vivenciam. Nesse sentido, muitos 
pais, ou responsáveis se encontram em sofrimento psíquico e o grupo deve ser considerado um espaço que propicie discussões sobre as suas próprias questões individuais e familiares.

A participação de profissionais da rede de serviços especializados ao atendimento de crianças, adolescentes e/ou família em diversas áreas favoreceu o conhecimento mais técnico ou teórico, assim como possibilitou um espaço de se colocar as angústias com o respaldo profissional, tendo a oportunidade de possíveis encaminhamentos para serviços especializados.

Verificamos também haver casos de correlação entre a qualidade dos cuidados afetivos-emocionais recebidos pelos pais em sua infância e o estabelecimento de suas identidades adultas, tendo por consequência a reprodução do mesmo padrão de cuidados com os filhos. Desse modo, são comuns expressões tais como: "eu apanhava com um pedaço de pau desse tamanho e acabei fazendo igual, não sabia fazer diferente" (sic). Essa questão é especialmente relevante, haja vista que possibilita aos pais retificar algumas condutas desfavoráveis ao desenvolvimento infantojuvenil. Quando isso acontece, beneficiam não apenas o adolescente internado, mas também os outros filhos que compõem o núcleo familiar.

Em contrapartida, existem pais pouco envolvidos com o processo de desenvolvimento dos filhos, sendo necessário sensibilizá-los quanto a sua importância e a sua responsabilidade nesse sentido. Alguns negam a própria responsabilidade em relação aos comportamentos dos filhos, deslocando-a integralmente para o próprio adolescente, atribuindo uma maturidade a este ainda não constituída. A esse respeito, Winnicott nos aponta que a constituição da personalidade do indivíduo é formada pela participação do ambiente em que a criança vive e os cuidados a ela conferidos. A criança saudável chega à adolescência equipada para atender os seus novos sentimentos, tolerar melhor as situações de apuros e resolver situações que envolvam ansiedade em demasia. A família e a escola exercem uma ação direta no desenvolvimento da criança e do adolescente, assim como o meio social, a confiança é a base nas relações entre o adulto e o adolescente.

Araújo (2007, p. 61) aponta que, para os adolescentes, a família tem papel essencial na promoção na segurança necessária ao turbilhão de acontecimentos vividos nesse 
período. Desta forma, para Winnicott (2005, p. 15), a vida em família é a base para os grupos com os quais os adolescentes terão a necessidade de conviver. Torna-se essencial que a família continue existindo para que o jovem possa rebelar-se contra ela, ou mesmo utilizá-la quando precisar se reassegurar.

Outros negam a situação real em que os filhos se encontram hoje, evidenciando os pontos positivos do adolescente de forma idealizada. É possível citar como exemplo dessa dinâmica a expressão de um casal parental acerca de seu filho. O pai dizia: "Como ele (o filho) pode estar aqui? Ele dormia nos meus braços, é uma criança" (sic). A mãe: "Se ele está aqui é por culpa dele mesmo, nós demos carinho para ele" (sic). A fala de outra mãe também ilustra a dinâmica mencionada: "Meu filho é educado, carinhoso, estudioso...". (sic)

Nesses casos, há acolhimento dessas expressões, porém, estímulo à reflexão de alternativas para lidar com a realidade sobre suas responsabilidades como pais. Muitos desses pais reconhecem suas condutas inadequadas, motivam-se para mudanças, mas não sabem como fazê-las, e as orientações técnicas, então, mostramse fundamentais.

Consideramos a adolescência como uma fase de desenvolvimento, os indivíduos mobilizam nos familiares, e a todos aqueles que cuidam, sentimentos contraditórios, como raiva e amor. No entanto, a relação dos adolescentes internados com a sua família é mais complexa, já que a própria condição de terem cometido atos infracionais expressa sérios conflitos de ordem psicoemocional, relacionados ao ambiente familiar o qual não se constituiu como facilitador ao desenvolvimento desses adolescentes em etapa evolutiva específica.

Além das reuniões com a família, o programa procura intervir na relação entre pais e filhos, visando ao seu fortalecimento, a partir de ações direcionadas especificamente aos adolescentes. Uma estratégia utilizada é o seu envolvimento na organização dos encontros, a partir de oficinas de confecção de presentes aos pais e de apresentações culturais com teor de homenagem aos familiares. Esses momentos são marcados pela afetividade e oferecem aos adolescentes a oportunidade de agirem de forma reparatória em relação aos prejuízos que acreditam ter causado aos pais em razão de suas condutas. 


\section{Considerações finais}

A importância deste trabalho é mostrar o programa desenvolvido no CENSE Londrina II, o qual oferece a possibilidade de intervenção junto à família dos adolescentes da instituição, com enfoque na melhoria e no fortalecimento das relações interpessoais, tendo em vista a harmonia da convivência familiar e a (re)constituição de um ambiente favorável ao desenvolvimento integral do adolescente em período egresso. Trata-se, também, de envolver a família nos processos socioeducativos dos filhos, dada sua importância e responsabilidade em todos os aspectos que envolvem o amadurecimento e formação destes.

Além do mais, trata-se de avançar em relação às modalidades de intervenção com as famílias, as quais, em razão das dificuldades em suas condições objetivas de vida, não encontram tão facilmente serviços que se propõem a abordar e a intervir para a melhoria na dinâmica de suas relações. Em que pesem as dificuldades desse tipo, apresentam além da necessidade, interesse por intervenções dessa natureza. Apesar de outros segmentos sociais também demandarem tais intervenções, são os menos favorecidos economicamente que têm menos recursos para encontrar apoio no caso de conflitos e problemas familiares.

A intervenção proposta para essas famílias possibilita o pensar sobre a função parental necessária à formação do indivíduo. Mas a própria intervenção desvela também a estas as falhas que aconteceram nesse primeiro ambiente. Esta revelação traz à tona diversos sentimentos de defesa como a negação das ações dos filhos, ou o não comprometimento com as atitudes e comportamentos destes. Tais defesas devem ser trabalhadas com os pais a fim de trazê-los à realidade objetiva, e desta forma poder ajudá-los no cuidado com os filhos com uma autoridade clara e sem ser agressiva. Muitas vezes, este processo é facilitado quando se encontram em grupos de pais na mesma situação.

Para Braga (2009, p. 51), é tarefa dos pais e professores cuidarem para que crianças e os adolescentes não estejam diante de autoridade fraca, de maneira a ficarem sem qualquer limite ou controle, e não deixarem que eles assumam a autoridade do ambiente. A agressividade em demasia, ou o sentimentalismo, é devastador para o 
desenvolvimento dos indivíduos. $\mathrm{O}$ adulto tranquilo é menos cruel, a agressividade gera o medo e o sentimentalismo contém uma negação inconsciente da destrutividade.

Podemos refletir sobre a agressividade ou o sentimentalismo tão prejudicial em que os jovens foram submetidos em seu primeiro ambiente, a saber, a família ou em outros ambientes como escola ou o bairro em que vivem. Porém, como profissionais também devemos trabalhar, em nós mesmos, essas questões de como lidar com tais adolescentes de forma a possibilitar uma sustentação teórica e emocional para os adultos que lidam ou lidarão em seu cotidiano.

Portanto, as alterações positivas nas condutas dos pais podem se reverter na melhoria dos cuidados dos outros filhos do grupo familiar, dessa forma, beneficiando a todos. Podemos dizer que essa intervenção apresenta também um caráter preventivo em termos de saúde psíquica, já que procura intervir em situações desfavoráveis à formação dessas crianças e adolescentes.

\section{Referências}

ABERASTURY, A.; KNOBEL, M. Adolescência normal: um enfoque psicanalítico. Porto Alegre: Artmed, 1981.

ABRAHAM, J. A linguagem de Winnicott. Rio de Janeiro: Revinter, 2000.

ARAÚJO, C. A. S. Uma abordagem teórica e clínica do ambiente a partir de Winnicott. 2007. Tese (Doutorado) - Pontifícia Universidade Católica de São Paulo, São Paulo.

BRAGA, C. M. L. Comunicação e isolamento: uma análise clínica de diários e blogs de adolescentes. 2009. Tese (Doutorado em Psicologia). Pontifícia Universidade Católica de Campinas, Campinas.

BRASIL. Decreto n. 99.710, de 21 de novembro de 1990. Promulga a Convenção sobre os Direitos da Criança. Brasília: Casa Civil, 1990.

Constituição (1988). Constituição da República Federativa do Brasil. Texto consolidado até a Emenda Constitucional n. 64 de 04 fev. 2010. Brasília: Senado Federal, 2010a.

. Lei 8.069, de 13 de julho de 1990. Dispõe sobre o Estatuto da Criança e do Adolescente e dá outras providências. Texto consolidado de 2010. Brasília: Casa Civil, 2010b.

BRASIL. Conselho Nacional dos Direitos da Criança e do Adolescente. Sistema Nacional de Atendimento Socioeducativo - SINASE. Brasília: CONANDA, 2006. Disponível em: 
<http://www.sedh.gov.br/sedh/.arquivos/.spdca/sinase_integra1.pdf>. Acesso em: 4 dez. 2010.

DAVIS, M.; WALLBRIDGE, D. Limite e espaço: uma introdução a obra de D. W. Winnicott. Rio de Janeiro: Imago, 1982.

INSTITUTO DE AÇÃO SOCIAL DO PARANÁ - IASP. Pensando e praticando a socioeducação. Curitiba, 2007. (Cadernos do IASP).

KNOBEL, M. Desenvolvimento psicológico: adolescência e saúde. 3 ed. São Paulo: Paris, 1999.

OUTEIRAL, J. Adolescer. Rio de Janeiro: Revinter, 2003. . Secretaria de Estado da Família e Desenvolvimento Social. Centro de Socioeducação Londrina II. Portaria n. 10/2010. Programa escola de pais do CENSE Londrina II. 2010.

SOIFER, R. Psicodinamismos da família com crianças: terapia familiar com técnica de jogo. 2 ed. Petrópolis: Vozes, 1982.

WINNICOTT, D. W. Conceitos contemporâneos de desenvolvimento adolescente e suas implicações para a educação superior e Imaturidade do adolescente. In: . O brincar \& a realidade (1968).Rio de Janeiro: Imago, 1975. p. 187-194.

Da dependência à independência no desenvolvimento do indivíduo. In: WINNICOTT, D. W. O ambiente e os processos de maturação: estudos sobre a teoria do desenvolvimento emocional (1963). Porto Alegre: Artmed, 1983. p. 79-87.

A tendência anti-social. In: . Privação e delinquência (1956). São Paulo:

Martins Fonte, 2002. p. 135-147.

. A preocupação materna primária. In: . Da pediatria à psicanálise (1956). Rio de Janeiro: Imago, Ed. 2000. p. 399-405. . O conceito do indivíduo saudável. In: Tudo começa em casa (1967). São Paulo: Martins Fontes, 2005. p. 3-22.

ZIMERMAN, D. Fundamentos psicanalíticos: teoria, técnica e clínica: uma abordagem didática. Porto Alegre: Artmed, 1999. 